\title{
O papel do tabagismo na doença periodontal
}

Leonardo Soares de Lima Nunes* Sônia Maria Blauth de Slavutzky*

\section{RESUMO}

\begin{abstract}
Cento e sessenta $\theta$ quatro militares foram examinados e responderam a um questionário com objetivo de buscar esclarecer a influência do tabagismo na Doença Periodontal. Os dados obtidos foram analisados em busca de informaçōes que ajudassem a esclarecer esta influência, usando para isto o índice Comunitário de Necessidade de Tratamento Periodontal (ICNTP).
\end{abstract}

\section{UNITERMOS}

Periodontia, doenças, tabagismo.

\section{Revisão da Literatura}

Existem vários estudos que demonstram a participação do fumo no processo da Doença Periodontal, porém, o mecanismo e processo pelo qual ocorre esta participaçăo ainda estão muito indefinidos. Alguns autores, como Bastian e Waite (3), demonstraram que os fumantes têm uma tendência a formação de placa mais veloz que os năo fumantes, mas esta diferença não foi estatisticamente significativa, assim como não houveram diferenças significativas em escores de gengivites nos dois grupos.

Entretanto, outros autores como Goutschin (7), concluíram em suas pesquisas que não fumantes são mais sensíveis periodontalmente do que os fumantes, que quanto mais cigarros são fumados por dia menos saudável é o indivíduo, e que o maior número de sextantes com sintomas mais graves de periodontite, nos fumantes é devido à redução da corrente sangüínea gengival causada pelo fumo. Clarke e Carey (4), em 1985, relataram que esta redução da circulação sangüínea na crista gengival dura de 2 a 3 horas após um cigarro ser fumado.

Além da ação na circulação periférica, o fumo, através da nicotina e seus metabólitos (principalmente a cotinina), como mostrado em estudos "in vitro", atua na resposta imune. A nicotina também afeta os fibroblastos por decréscimo na produção de colágeno, prejudicando a sua secreção (5). Esta substância tem um tempo médio de presença no plasma de 2 horas, após isto, é metabolizada em cotinina, cujo tempo médio é de 9 horas (9).

Nos estudos "in vitro", acima citados, foi demonstrado que o tabaco produz efeitos prejudiciais em vários componentes do sistema imunológico, incluindo depressão fagocitária e quimiotaxia dos polimorfonucleares (PNN), da cavidade bucal, decréscimo da viabilidade linfocitária e produção reduzida de anticorpos. $E$, a degranulação dos mastócitos parece ser estimulada favoravelmente pelos efeitos do fumo de tabaco (6).

Nas décadas seguintes vários pesquisadores empenharam-se no estudo da relação do fumo com a Doença Periodontal, e através de estudos onde os indivíduos submetidos possuiam um nível de higiene oral semelhante, entretanto, não se encontraram dados que significassem uma maior disposição de cálculo ou aumento de gengivite nos fumantes em relação aos não fumantes (10).
Ismail e colab. (8), avaliaram a relação de fumo com a Doença Periodontal em 300 indivíduos, para isto ajustaram todos os valores principais obtidos às variáveis que confundiam os dados das pesquisas anteriores, entre eles estão a idade, higiene oral, status sócio-econômico, sexo, raça e frequência de escovação dentária, usando modelos múltiplos de regressão linear. Como resultado tiveram os fumantes maior índice P.I. (Índice Periodontal) em todos os grupos de idade e, significativamente mais altos escores de debris, cálculos e higiene oral. Os dados sugerem que o fumo tem uma ação direta e independente com a Doença Periodontal, embora menos forte que com a associação da higiene oral e idade com a mesma doença (10).

Apesar de estudos em humanos não mostrarem uma relação significativa entre fumo e formação de placa, no que se refere à proporção de bactéria G- e $\mathrm{G}+$, ou bactérias aeróbicas e anaeróbicas, estudos "in vitro", como o de Bardell e Smith (2), 1979 e, Bardell (1), em 1981, deixaram claro que o fumo influencia na

\footnotetext{
* Acadêmico da FO/UFRGS.

* Professora Orientadora - DEOPS FO/UFRGS
} 
seletividade bacteriana, sendo que as bactérias G- são mais susceptíveis que as $\mathrm{G}+(7)$.

A Toxicidade do Fumo está tanto na fase de liberaçăo de gás/vapor quanto no resíduo, que podem induzir $50 \%$ ou mais de inibição da função dos neutrófilos orais. As duas mais potentes substâncias presentes no gás/vapor são acroleínas e cianidos que inibem a função leucocitária (2).

\section{Material e Métodos}

Um total de 164 militares (soldados e cabos pertencentes ao $3^{\circ}$ Regimento de Cavalaria de Guarda Marechal Osório e $8^{\circ}$ Batalhão Logístico), participaram do presente estudo, onde se realizou um questionário $\mathrm{e}$ exame clínico. A escolha desta amostra embasou-se nas características em comum apresentadas pelos indivíduos. Entre elas as mais importantes são: mesmo sexo, idades semelhantes, alimentação básica igual, mesmas condições para executar a higiene oral, e em condições de vida temporariamente parecidas.

Para o exame clínico foi utilizado o índice ICNTP com uma modificação, que consiste na união dos códigos 2 e 3 em um único código, isto devido à: apenas em situaçōes raras (quando a margem coincide com a junção cemento-esmalte) os resultados das medidas de profundidade da bolsa dão informaçōes adequadas, considerando a extensão da perda de inserçăo. Por exemplo, um edema inflamatório pode ocasionar o aumento da gengiva livre, resultando em um deslocamento coronal da margem gengival sem a migração concomitante do epitélio dentogengival para um nível apical a junção cementoesmalte. Em outra situação, a perda da inserção pode ter ocorrido sem o aumento concomitante da profundidade da bolsa, entre outras razōes, como por exemplo, os vários erros inerentes a sondagem. Os locais escolhidos para a coleta de dados foram o $3^{\circ}$ regimento de Cavalaria de Guardas Marechal Osório, situado na Av. Bento Gonçalves, 3080 - Porto Alegre; e o $8^{\circ}$ Batalhăo Logístico situado na Av. Bento Gonçalves, 3156 - Porto Alegre.
Os resultados dos questionários e exames clínicos foram analisados estatisticamente através do Teste de Significância Khi quadrado. Por este método pode-se medir as divergências existentes entre as frequências calculadas e as observadas. Como níveis de significância foram usados o $\mathrm{P}=0,05$ e $\mathrm{P}=0,01$, equivalentes a $5 \%$ e $1 \%$ de probabilidade de erro, respectivamente. ra $P(0,01)=21,7$ e $P(0,05)=16,9$ entre os fumantes e, $\quad\left(X_{2}=114\right.$ para $P(0,01)=23,2$ e $P(0,05)=18,3$ entre os não fumantes).

O gráfico 2 relaciona o comportamento dos indivíduos quanto ao hábito de fumar (fumantes, ex-fumantes e nunca fumaram) e o índice ICNTP. Esta relação năo é significativa $\left(X_{2}=9\right.$ para $P(0,01)=16,8$ e $P(0,05)=18,5)$.

\section{Fumantes e Nao Fumantes: Idade X ICNTP Porto Alegre. 1991.}

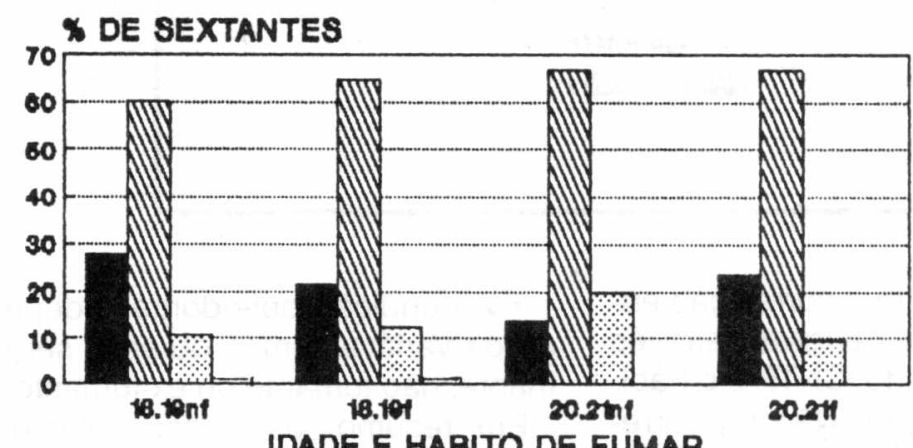

IDADE E HABITO DE FUMAR

Codloo ICNTP

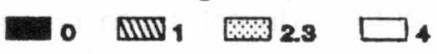

GRAFICO 1

\section{Resultados e Discussão}

No gráfico 1 encontra-se a relação entre o hábito de fumar, a idade e o índice ICNTP, o que é estatisticamente de alta significância $\left(X_{2}=59,26\right.$ pa-

\section{Comportamento quanto ao fumo $X$ ICNTP Porto Alogre. 1991.}

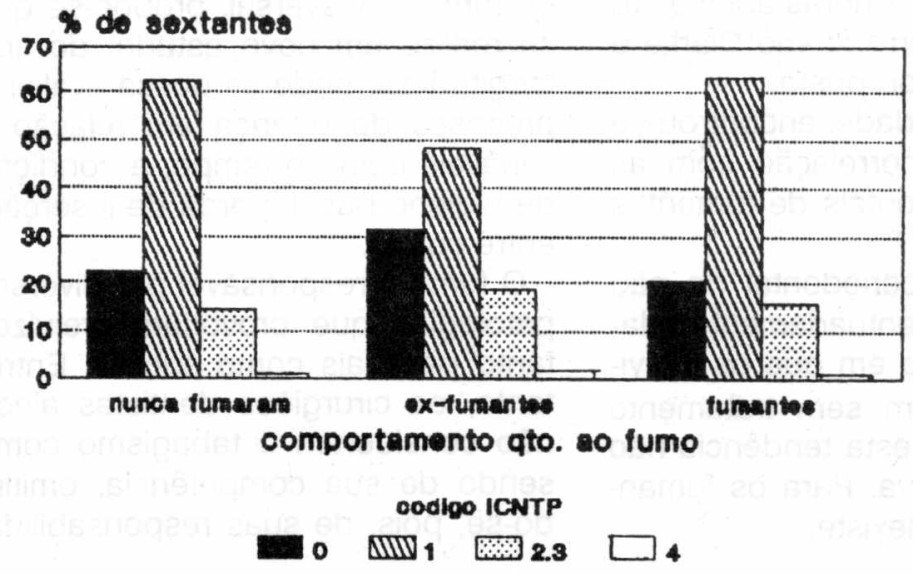

GRAFICO 2 


\section{Sangramento X Fumantes e Nao Fumantes Porto Alegre. 1991.}
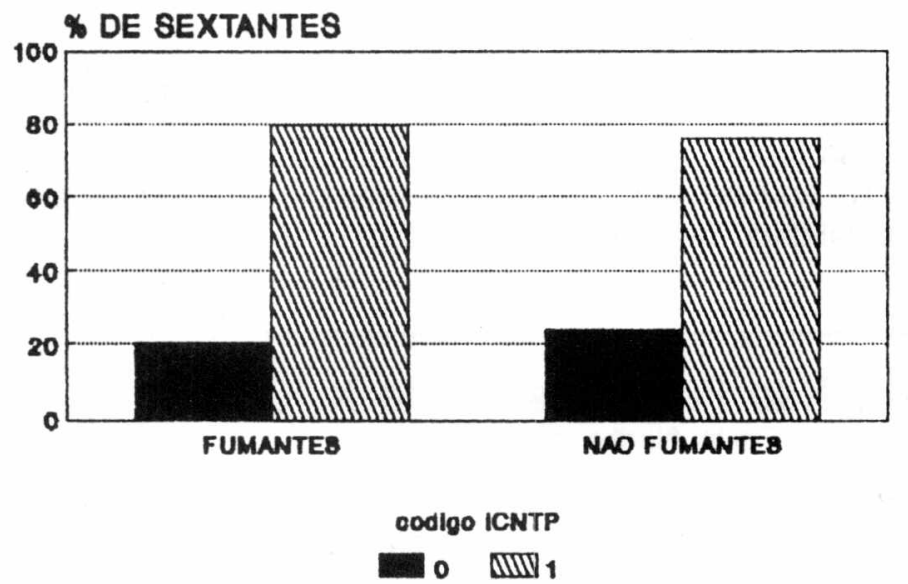

\section{GRAFICO 3}

O gráfico 3 mostra a correlação entre sangramento gengival através dos códigos 0 e 1 do ICNTP e o hábito de fumar ou não. Não há correlaçăo entre a presença ou ausência de sangramento com o hábito de fumar ou não $\left(X_{2}=1,46\right.$ para $P(0,01)=6,6$ e $P(0,05)=3,8)$.

\section{Conclusão}

A partir dos dados avaliados estatisticamente podemos dizer que:

- Não se comprovou neste estudo que exista correlação entre o número de cigarros fumados ao dia com a condição periodontal, contrariando os achados de Goutschin".

- Não se comprovou tão pouco a diminuiçăo do sangramento na crista gengival, por redução da circulação sangüínea, de 2 a 3 horas após o ato de fumar um cigarro, como Clarke e Carey (6) haviam proposto.

- Em relação a idade, encontrou-se uma acentuada correlação com as condições periodontais de fumantes e não fumantes.

- A condição periodontal de não fumantes está acentuadamente relacionada ao tempo em que os indivíduos permanecem sem tratamento periodontal, mas esta tendência não se mostra definitiva. Para os fumantes esta relação inexiste.
- A condição periodontal independe da variável fumar, ou seja, ser fumante, não fumante ou ex-fumante.

Em resumo, os dados coletados não demonstram correlação clara entre o Tabagismo e a Doença Periodontal, tanto em relação ao número de cigarros fumados por dia como ao fato de ser fumante, não fumante ou ex-fumante. Contudo, alguns dados como a condição periodontal não estar na dependência do tempo de recebimento de tratamento periodontal para o fumante e ser dependente para os não fumantes, demonstram uma possivel relação entre ambos.

A condição de Doença Periodontal está na dependência da idade.

Tendo este estudo sido realizado de forma transversal, propõe-se que se realize um novo estudo, do tipo longitudinal, onde se possa avaliar o processo da doença em relaçăo à variáveis como o tempo, a condição de higiene bucal, perda de inserção, entre outras.

O fumo é responsável por diversas patologias que provocam prejuízos tanto pessoais como sociais. Entretanto, os cirurgiōes dentistas ainda não consideram o tabagismo como sendo de sua competência, omitindo-se, pois, de suas responsabilida- des como profissionais da saúde. Portanto o combate ao fumo deve estar incluído com ênfase em todas as Campanhas de Saúde, Odontológicas ou Médicas.

Este trabalho participou do Concurso "Prêmio Estímulo Kolynos", de 1991, patrocinado por Anakol Indústria e Comércio.

\section{REFERÊNCIAS BIBLIOGRÁFICAS}

01. BARDELL, D. Viability of six species of normal oropharyngeal bacteria after exposure to cigarette smoke "in vitro". Microbios, s.l., 32:7, 1981.

02. BARDELL, D. \& SMITH, J.E. An "in vitro" study of mixed population of normal oropharyngeal bacteria to cigarette smoke. Microbio, s.l., 26159, 1979.

03. BASTIAN, J.R. \& WAITE, I.M. Effects of tobacco on plaque development and gengivitis. J. Periodontal, New York, 49:480-482, 1978.

04. CLARKE, N.G. \& LAREY, S.E. Etiology of chronic periodontal disease: alternativee perspective. J. American Dent. Assoc., Chicago, 110:689-1991, 1985

05. COLMAN, G. et alii. Cigarette smoking and the microbial flora of the mouth. Aust. Dent. J., sidney, $21(2): 111,1976$.

06. CUFF, M.J.A. et alii. The presence of Nicotine on root surfaces of periodontally diseased teeth in smokers. Journal os Periodontology, EUA, $60(10): 564-569$, 1989.

07. GOUITSCHIN, J. et alii. Association of smoking with periodontal treatment needs. Journal of Periodontology, EUA, 61 (6):364-367, 1990

08. ISMAIL, A.I. et alii. Epidemiologic patterns of smoking and periodontal disease in the United States. J. Am. Dent. Assoc., Chicago, 106:617, 1983

10. PINDBORG, J.J. Gingivitis in military personnel with special reference to ulceromembranous gingivitis. Odontol. Tidskr, s.l., 59:403, 1951 